\title{
A psychophysical study for evaluating a model of human olfaction
}

\author{
Lisa Kroll', Christiane Wegner, Amir Madany Mamlouk \\ From 1st International Workshop on Odor Spaces \\ Hannover, Germany. 4-7 September 2013
}

My research project in the field of olfaction is based on a theoretical model of early olfactory processing that we used to design a psychophysical study. The theoretical model suggests that regions in the olfactory bulb, so called modules, can be viewed as single characters of an encoding alphabet for the detailed understanding of epitope maps in the olfactory bulb. For the module generation, non-negative matrix factorization (NMF) was applied to [C14]-deoxyglucose-uptake-images of the olfactory bulb of rats.

In the current study, I am seeking for a correlation between the odor quality of compounds and their corresponding modules. So the hypothesis to be tested here is: Odorants that activate similar patterns of modules are likely to be perceived as being more similar than others. To test this hypothesis, I performed a double-blind psychophysical study on humans. For the study, I selected a choice of 18 odorants which can be assigned to five different modules (of the underlying model of nine modules). Each odorant was diluted such that it was at the lower detection threshold of a panel of test subject. The odorants were offered to human subjects in all possible 171 pairwise combinations and the subjects were asked to rate whether or not the odorants smell similiar. All subjects at least participated in one session, most subjects performed two trails of 30 different odorant pairs. The pairs were randomly assigned and the bottles were coded, so the participants had no knowledge about the contents of each bottle. A subset of participants was measured twice the same session. First results show, that there is a significant correlation between the perceived odor similiarity and the proposed modules, i.e. my study lends color to his hypothesis. Thus, similarities of odor substances may be predicted just by using similarities measured on these modules. The study has been

Institute for Neuro- and Bioinformatics, University of Luebeck, Germany

performed with three groups of participants independently (21 and 26 subjects with 60 pairs, and 11 subjects that were exposed to 30 pairs twice). The correlation could be observed in all three trials.

Published: 16 April 2014

doi:10.1186/2044-7248-3-S1-P6

Cite this article as: Kroll et al: A psychophysical study for evaluating a model of human olfaction. Flavour 2014 3(Suppl 1):P6.

Submit your next manuscript to BioMed Central and take full advantage of:

- Convenient online submission

- Thorough peer review

- No space constraints or color figure charges

- Immediate publication on acceptance

- Inclusion in PubMed, CAS, Scopus and Google Scholar

- Research which is freely available for redistribution 